\title{
Facilitating the Transition from Passive to Active Community Forest Management: Lessons from Rapti Zone, Nepal
}

\author{
N.P. Yadav*, K.P. Yadav*, Kamlesh K. Yadav* and Nirmal Thapa* \\ * Livelihoods \& Forestry Programme (LFP), Nepal \\ Corresponding author: n-yadav@lfpmw.org.np
}

\begin{abstract}
This paper demonstrates that a transition from passive to active management of community forest is possible by adopting joint learning processes among local forest user groups, forest officials and local non-governmental service providers. Such an approach has the potential to address several issues that underlie and characterise passive management namely: underutilisation of forest, protection oriented forest management, overstocked forest (dense) vis-a-vis deficit in supply of forest products, and poorly designed silvicultural practices. Passive management is attributed mainly to the poor planning of forest management, inadequate and restrictive forest inventory guidelines and limited recognition of the forest management knowledge of locally trained resource persons. We present evidence of the processes and outcomes of active management being promoted by Community Forest User Groups (CFUGs) in Nepal. The transition to active forest management is demonstrated through an assessment of revisions made in the community forest Operational Plans (OP). Key revisions identified include, among others: defining objectives of forest management considering people's choices and locality factors, site-specific forest management treatments, development of product utilisation plans, provisions for Non-timber Forest Products (NTFPs) management and conservation of biodiversity and water resources.
\end{abstract}

Key words: active forest management, operational plan, local resource person, forest inventory, sustainable forest management

\section{INTRODUCTION}

There is consensus among the advocates of community forestry, researchers and service providers that Community Forest User Groups (CFUGs) in Nepal are largely adopting protection-oriented management. This has been attributed to unclear silvicultural provisions in their forest Operational Plans (OPs) and to low levels of community awareness about the provisions made in their plans. This paper's focus is to show the various ways in which these constraints to active management of community forest are being addressed.

A major cause of passive management of community forests (CF) is conservative operational plans, prepared with minimal participation of users and with limited sitespecific information about forest condition. Unfortunately, the national CF inventory guidelines do not properly recognise differences in forest condition thus these guidelines have become a constraint to active forest management. For the purposes of active forest management, the forest inventory guideline is the key which determines the Annual Allowable Cut (AAC). However, constraining provisions are imposed in OPs by technical misinterpretation of the inventory. Due to improper estimation of $A A C$, there are many situations in community forestry where passive forest management or protection oriented management is promoted. In the long term, this will contribute to changing the forest composition e.g. valuable and light demanding species are replaced in CFs by shade bearer species and there is less diversity in diameter classes.

In this context, the concept of active forest management has been introduced in Livelihoods and Forestry Programme (LFP) areas. This paper demonstrates the practice of active forest management by improving action learning processes among local forest user groups, forest officials and local non- 
governmental service providers. The existing practice of active forest management follows the principles of Sustainable Forest Management (SFM).

The objective of this paper is to share our experiences of active forest management and of our attempts to address the constraints imposed by the forest inventory guidelines. We also explore several observations and studies related to forest management practices in the LFP area and analyse the factors that affect SFM. Firstly, the general concept of active forest management in the context of community forestry is discussed followed by a justification for writing this paper. Then follows a description of our methodology. Part four covers LFP's approach to active forest management with the results and discussions which form the core of the paper. This is followed by distillation of learning in part five whilst part six gives conclusions and recommendations to further promote active community forest management in the light of current issues and debates.

\section{BACKGROUND}

The last three decades of the community forestry programme have emphasised group formation, handing over of national forests and protection by limiting the utilisation of forest resources. This was mainly because degraded and poor forests were handed over, and many CFUGs were reluctant to cut green trees in their CF. Even where CFUGs did receive forests in good condition with mature trees, protection became the sole objective resulting in passive management. The silvicultural treatments mentioned in most OPs do not include the required level of operations to promote SFM including the optimum levels for forest product harvesting. Over the last few years community forestry has entered a utilisation phase that could result in CFs becoming one of the major sources of timber in future. Analysis shows that CFs could potentially produce more timber than Nepal can consume, hence, export of timber to international markets could significantly increase Nepal's national revenue.

The Master Plan for the Forestry Sector (MPFS 1988) strategically mentioned the need to promote community forestry particularly in middle hills by handing over patches of national forest to local communities to fulfil their basic forest product needs. The Government of Nepal (GoN) mostly handed over barren and depleted forests as CFs necessitating intensive care and protection during the initial period after handover. The CFUGs focused more on protection so that even those with productive forest, became protection oriented leaving the growing stock to accumulate. Yadav et al. (2003) recognised that the main problem in hill CFs is under-utilisation of forest resources at the cost of the livelihoods of local people, the national economy and often adjacent national forests. Since many CFs are still protection oriented, the community forestry programme has been challenged and its success questioned by commentators e.g. Nurse et al. (2004). In the field it is observed that most OPs are protection oriented, and user groups make only minimum use of their CFs to meet their needs by removing shrubs, dead, dying trees, and by cutting branches. Thus they just meet their subsistence needs but do not utilise the full productive potential of the forests. Furthermore, protection-oriented CF management restricts access of poorer households to fodder and fuelwood (Yadav et al. 2003).

Forest legislation has made the preparation of OPs mandatory before handing over government forests to CFUGs. However, the management prescriptions in most OPs are very conservative (Acharya 2002, Kanel and Kandel 2004, Shrestha and Amatya 2000). Although the Forest Act (1993) has legitimised CFUGs as managers and users of CFs under the guidance of OPs developed by themselves, many CFUGs put emphasis on protection and less on actual management (Branney and Yadav 1998). Most OPs lack adequate provision for silvicultural prescriptions according to forest type and 
stocking. They simply mention the harvesting activities for each forest block and the time frames but lack any mention of required silvicultural inputs. Also, the silvicultural systems prescribed in their operational plans largely focus on timber production.

The Timber Improvement and Silvicultural Component (TISC) under the Department of Forest (DoF) has produced an ecological map of Nepal, but its use has been limited to extension only. Suwal (2004) highlights the importance of these maps and suggests that the use of ecological and district forest maps can be a breakthrough for appropriate planning in the management of CFs. Shrestha and Amatya (2000) stated that after years of protection, CFs have increased their growing stock and hence have potential to increase their product yields. It has been estimated that the economic benefits of active management of CFs would be more than four times greater than the benefits from passive management (Shrestha and Amatya 2000).

The DoF has prepared CF Guidelines as well as CF Inventory Guidelines to facilitate the process for preparing CFUG Constitutions and OPs. The CF Inventory Guidelines, revised in 2004/05 are being implemented by DFOs and other agencies involved in CF development. However, the agencies involved in their implementation have not reflected sufficiently on technical and political constraints in preparation, implementation and revision of OPs in order to make them more user-friendly and practical. LFP has been supporting the implementation of these guidelines with some modifications together with Range Post (RP) staff and Local Resource Persons (LRPs) at field level. Further, LFP Mid-west is practicing an active forest management joint action-learning process together with government officials and Nongovernmental Organisations (NGOs) involved in the forestry sector.

The GoN has identified the role of NonGovernment Service Providers (NGSPs) in the implementation of the community forestry programme (now mentioned in the 10th 5-Year
Plan and the current Interim 3-Year Plan) and the Ministry of Forest and Soil Conservation (MFSC) prepared NGSPs Guidelines. Several organisations such as LFP, the Biodiversity Sector Programme - Siwalik and Terai (BISEPST), the Forest Partnership Program (FPP) of Care Nepal, the Nepal Swiss Community Forestry Programme (NSCFP) have been supporting local NGOs to implement forestry activities. The involvement of local NGOs has been done in many ways: a) supporting DoF in programme implementation, b) capacity building of local institutions involved in forestry, c) the development of LRPs, and d) facilitating the process of decentralization. LFP has been supporting the DoF community forestry programme implementation by involving local LRPs through NGOs for social mobilization as well as for technical support for OP preparation and implementation. The role of LRPs has been widely accepted by both District Forest Offices (DFOs) and CFUGs.

\section{METHODOLOGY}

This paper has been prepared based on a literature review; on reflections and analysis of the practices from the LFP areas; on conclusions from various joint forums; on analysis of OPs (new and old); on analysis of provisions of the CF Inventory Guidelines; on results from demonstration plots and on experiences of forestry professionals working in the area.

This paper draws heavily on the provisions mentioned in the OPs of a sample of 302 CFUGs and on findings of technical review workshops and action research initiated since the start of LFP in 2001.The paper is also based on various minutes/decisions made by CFUGs when implementing their OPs particularly those concerning silvicultural practices. The process of OP revision to improve silvicultural practices is also highlighted. Data analysis from various demonstration plots along with analysis by forestry professionals are integral parts of this paper. In addition, common understandings amongst various stakeholders about active forest management and the process of 
mobilising the LRPs to provide technical support to CFUGs have also been taken as empirical bases for our paper.

This paper includes information received during discussions with CFUGs about their management objectives and classification of their forest crops into saplings, poles and trees (as stated in the guidelines) even though these may not have been applicable from a management point of view nor congruent with local forest use patterns.

\section{UNDERSTANDING ACTIVE FOREST MANAGEMENT}

Principally and legally, forest users are organised to manage forest resources collectively for the conservation and optimum utilisation of their forest. The aim of active forest management is to obtain optimum levels of desirable forest products through the application of appropriate silvicultural systems as specified in the OPs. This means that forest users need to conduct silvicultural operations regularly and in planned ways to achieve the defined objectives of forest management. Active forest management is a process which requires active involvement of $\mathrm{CF}$ users to implement their OPs. It is based on the principles of SFM but gives space for incorporation of local needs and aspirations. It uses a participatory forest management approach with adaptation of pure, theoretical scientific management prescriptions to make them more CFUG friendly.

Legally CFUGs should prepare and implement their own forest OPs with necessary technical support coming from forest technicians. In practice, forest technicians often prepare the OPs with only limited levels of communication with local elites and usually less with other users. This reduces ownership by CFUGs of the $\mathrm{OP}$ and its implementation and, in consequence, many CFUGs consider the OP as a legally required document rather than one to be followed in an operational sense.
The CF is managed by users to fulfil their economic and environmental needs. Forest products include fuelwood, grass, fodder, leaf litter, timber and animal bedding materials. Besides these, users are equally concerned with the protection of soil, water and other valuable resources such as NTFPs and naturally regenerated plant species in the community forest. People-oriented forest management implies that forest management objectives are based on peoples' needs and that forest development activities are carried out by the users (Yadav 2004). The CF management combines current scientific and conventional knowledge of forest management and is necessary for the long-term supply of forest products to benefit CFUG members. Such benefits are only possible with regular supplies of forest products which meet users needs and also generate a regular income from the marketing of any surplus.

In the process of community forestry development, so-called 'second-generation issues' need to be addressed by approaches such as SFM, good forest governance and livelihoods improvement. These are all necessary to ensure the sustainability of the community forestry programme. However, this paper concentrates on the prospects and practices of active forest management for contributing to SFM and on the active role of CFUGs in managing their CF resources and meeting their varied demands. Together these constitute the objectives of forest management and defines the term 'Active Forest Management'.

\section{The Active Forest Management Process in Livelihoods and Forestry Programme Areas}

Livelihoods and Forestrey Programme Mid-west has been practicing field based coaching for CFUGs to promote active forest management. This has shown positive results and has created an opportunity to learn from demonstration plots that were previously established in CFs for different purposes. This includes the effects of 
plot management for different objectives. Although the effects of thinning and coppicing operations have shown positive results on the ground, there is a lack of an institutionalised documenting system and only a few demonstration plots were properly established with defined silvicultural operations and by maintaining a regular measurement records. This process is gradually eliminating protectionoriented perceptions and practices of CFUGs through 'learning by doing' and through demonstration effects.

\section{Establishment of Demonstration Plots}

Data from a demonstration plot established in Rapti CF (Dang District) in 2000 in site quality-II of pole-stage Sal forest is given in Table 1. This shows that stand growth in the control plot and in plots with different silvicultural treatments differs significantly, with all treated plots sharing marked increase in mean basal area. In addition, since products are annually extracted from plots with silvicultural treatment, users are able to get additional benefits. Plot 3 (with widest spacing) has the highest annual growth for every measurement. Once this result was shared with CFUGs, it helped to accelerate silvicultural treatments in CFs.

Table 1: Results and Trend of Growth

\begin{tabular}{|l|r|r|r|}
\hline $\begin{array}{l}\text { Demo plot } \\
\text { characteristics }\end{array}$ & \multicolumn{3}{|c|}{$\begin{array}{l}\text { Percent mean annual growth in } \\
\text { basal area in different periods }\end{array}$} \\
\cline { 2 - 4 } & $2000-02$ & $2002-08$ & $2000-08$ \\
\hline $\begin{array}{l}\text { Plot 1, 2X2 m } \\
\text { spacing }\end{array}$ & 19.0 & 6.2 & 10.9 \\
\hline $\begin{array}{l}\text { Plot 2, 3x3m } \\
\text { spacing }\end{array}$ & 17.0 & 7.4 & 11.5 \\
\hline $\begin{array}{l}\text { Plot 3, 4x4m } \\
\text { spacing }\end{array}$ & 20.6 & 12.0 & 17.5 \\
\hline Plot 4, control & 14.7 & 4.3 & 9.8 \\
\hline
\end{tabular}

In the initial two years the annual increment is higher than in other years and the Mean Annual Increment (MAI) in the period between 20002008 is greater than 2002-2008.
The revised 'Guidelines for Community Forestry Development Programme' requires a forest inventory, a growing stock estimate, the calculation of the MAl and the calculation of an annual harvestable amount of different forest products or AAC. However, with this, it is doubtful if the full potential of forests can be used because MAI is estimated based on the condition of forests managed passively. Results of such demonstration plots challenges this way of prescribing management options. Silvicultural treatments at different stages of forest growth are needed to enhance forest condition. This is the stated primary aim of the DoF in the guidelines. However, in government managed forests demonstration plots to develop the skills and confidence of DFO staff in applying appropriate silvicultural treatments has not been practiced. In CFs, the result of the improper silvicultural treatments being prescribed is a generation gap in forest stands, and forest composition is changing as undesirable species replace those which are most preferred by local people.

"Niti vs Niyat" i.e. policy vs. attitude could be a useful analytical aspect for community forestry in Nepal. Even though the "niti" is good, the "niyat" of the implementer is not encouraging, and most often the tendency is to avoid rather than putting efforts into management improvement. If regeneration of species is ignored during forest operations, it will be a great loss to the respective CFUGs as well as the country in the long term. Regeneration is very important for SFM because it ensures future productivity. Harvestable amounts of forest products, in terms of quantity and quality, depend on forest condition. The importance of regeneration is now understood by the CFUGs who have established demonstration plots most of which show that opening up the forest canopy allows regeneration to occur and is thus considered as a priority activity (Suwal 2004). Establishing silvicultural demonstration plots is an approach that acts as a laboratory where both the indigenous and the scientific silvicultural practices are combined in a small 
scale learning ground. These demonstration plots will develop the confidence and capacity of CFUGs in silvicultural treatments during management of their CFs. The activities in LFP areas are similar to those proposed by Suwal (2004) and additional focus on prescriptions in OPs for regeneration promotion ensures that they are being properly implemented.

\section{Participatory Field Based Coaching}

The CFUGs are obliged to carry out an inventory of their CF to calculate the AAC and include this in their OPs. The idea is to ensure a sustainable harvest within the limits of their annual increment. However, in natural forest the first harvest consists of accumulated timber capital, which might have built up over a long period of time. The CFs of all different conditions are protected and there is therefore congestion because of this accumulated growing stock. The AAC calculated using the CF inventory guidelines is not appropriate in these cases. Unfortunately, due to the limited knowledge and skills of the CFUGs, and insufficient external technical support for them smooth implementation of the OPs is constrained. Consequently, CFUGs face legal and technical problems for securing an optimum level of harvesting and utilisation. The joint action learning team in LFP Mid-west identified such gaps and made recommendations for addressing them for DoF and at ministry level i.e. in national policy making.

The LFP Mid-west began the work of demonstrating such results to accelerate active forest management at CFUG level through a participatory process. To ensure wider acceptance the following steps were followed:

- Developed common understanding among stakeholders on active forest management;

- Developed active forest management coaching guidelines and other extension materials such as posters, booklets, etc.;
- Trained field staff, i.e. local facilitators and RP staff; and

- Coached field staff or facilitated active forest management in each CFUG as per coaching guidelines.

Through practice and collective reflection, a 1page user friendly coaching guideline was prepared. This included:

- Selection of a maximum of 30 participants, based on the criteria of inclusion - 50 percent women;

- Discussion on the needs and expectations of the CFUGs;

- Analysis of OPs, i.e. identifying the condition of the forest, management objectives of each block and of potential activities;

- Implementation of provisions for silvicultural treatments through mobilisation of users; and

- Monitoring of work: harvesting and forest product distribution and record keeping by the CFUGs.

\section{The Role of Non-governmental Service Providers in Active Forest Management}

The present structure and technical capacity of the Department of Forests cannot satisfy the ever-increasing demand for forest inventory and technical inputs for silvicultural treatments in CFs. This creates delays in OPs revision and handing over of CFs (Kanel and Kandel 2004). The Government takes sole responsibility for providing technical support to CFUGs even though its capacity is very limited. Although CFUGs are legally autonomous organizations which could outsource such technical services, there is no established system for doing this. There is thus a need to involve the NGO sector in the provision of services for CFUGs. This is also consistent with the polycentric approach of governance as spelled out in the $10^{\text {th }}$ Plan (Kanel 2004). Accordingly, CFUGs need to be liberalised so that civil society and private sectors can provide both technical and social 
services to them. The concept of developing and mobilising LRPs evolved out of this approach. The forestry regulations give CFUGs the autonomy to acquire services from anywhere they want but not all DFO officials recognise this. Some DFO staff are concerned that the LRPs are developed to replace them, but most of the forestry officials in the LFP area are supportive of this LRP approach and LRPs are encouraged to provide services to CFUGs. The LRPs are trained, and able to deliver a very satisfactory level of service. Mr Resham Upadhaya, the Chairperson of Munal CFUG in Rim VDC, Salyan District pointed out that:

"Our CF OP expired 3 years ago. We made a decision to amend the $O P$ and sent a request to the range post. However, due to their workload and other priority works they could not help us to amend the OP. This year, a trained LRP from our own CFUG successfully amended the $O P$ and the provisions of this $O P$ are now already being implemented".

\section{FINDINGS AND DISCUSSIONS}

Several factors constrain active forest management including: regulatory, institutional, theoretical, behavioral and practical knowledge and skills. We will discuss each of these factors and alongside the new interventions in LFP areas to promote active forest management through harmonising forest inventory, revising existing OPs, improving silvicultural practices and increasing forest product utilisation.

\section{The Situation before Active Forest Management Interventions}

Protection oriented forest management has its roots in the control by government forestry institutions e.g. permission is sought from the DFO every year to conduct annual forest operations particularly harvesting. As the blueprint (format-oriented) operational plans contained only vague options and operations CFUGs were motivated to harvest timber and to sell it outside their CFUGs where transportation was not a problem. They had less interest in regular silvicultural treatments to improve forest condition. The custom of opening the forest weekly for fuelwood collection is practiced but it is not clearly outlined in the OP. Thus in terms of the current practices for forest product harvesting and distribution, poor households were losing out since if they wanted to collect forest products they had to invest every Saturday for collecting dry branches as fuelwood.

\section{Forest Inventory Issues: Reconciling Regulatory, Scientific and Institutional Issues}

The inventory guidelines were revised in 2006 . They recommend that $10-29.9 \mathrm{~cm}$ diameter classes are considered as poles. According to the guidelines this entire pole category should be included in the calculation of growing stock and the AAC is prescribed based on the MAI of these which is not technically applicable in most situations. Similarly the guidelines recommend that all stems $>30 \mathrm{~cm}$ diameter class fall into the tree category.

The methods for forest resource assessment in the CF should be clearly understood by CFUGs so that they can fully participate in the forest inventory and give their views on forest management options. A 'plot card' was developed so that users could easily understand and define the age of each forest stand, e.g. seedling, sapling, large sapling (ballaballi), pole or tree. This is an age gradation method and trees are categorised according to their diameter or girth class (which is different from assuming an even distribution of diameter classes). Such disaggregated information about features of the forest, support recommendations for silvicultural treatments (Yadav 2004). In a workshop, a team of technicians discussed dividing poles into three categories: 10-14.9 cm dbh (small ballabali), 15$19.9 \mathrm{~cm}$ dbh (large ballabali) and 20-29.9 cm $\mathrm{dbh}$ (poles). Furthermore, the tree category was also been divided into various classes: $30-40 \mathrm{~cm}$ $\mathrm{dbh}$ (tree), 40-50 cm dbh (mature tree) and > $50 \mathrm{~cm}$ dbh (over-mature tree). This descriptive format now provides a clearer picture of the 
current composition of the forest stand which helps in drawing up site-specific prescriptions. The format was changed after long discussions during the training of DFO staff and LRPs. At the beginning, most of them disagreed with these changes because they implied a different classification system from those approved by the ministry. However, after much discussion a consensus was reached and changes favored these proposed guidelines.

Table 2: Inventory and AAC for Poles and Trees (Makhan Takuri CFUG, Dang Block No: 3) According to CF Inventory Guidelines

\begin{tabular}{|c|c|c|c|c|c|c|}
\hline \multirow[t]{2}{*}{ SN } & \multirow[t]{2}{*}{ Description } & \multicolumn{4}{|c|}{ Diameter class $(\mathrm{cm})$ and no. per ha } & \multirow[t]{2}{*}{ Total } \\
\hline & & 10-14.9 & $15-19.9$ & 20-29.9 & $30-55$ & \\
\hline 1 & No. per ha & 509 & 429 & 69 & 135 & 1,142 \\
\hline 2 & Volume per ha $\left(\mathrm{m}^{3}\right)$ & 24.2 & 42.9 & 28.9 & 160.2 & 256.2 \\
\hline 3 & $\begin{array}{l}\text { Annual volume increment } \\
\left(\mathrm{m}^{3} / \mathrm{ha} / \mathrm{yr}\right)\end{array}$ & 0.97 & 1.72 & 1.16 & 6.41 & 10.25 \\
\hline 4 & $\operatorname{AAC}\left(\mathrm{m}^{3} / \mathrm{ha} / \mathrm{yr}\right)$ & 0.73 & 1.29 & 0.87 & 4.80 & 7.69 \\
\hline 5 & Average vol./tree $\left(\mathrm{m}^{3}\right)$ & 0.05 & 0.10 & 0.42 & 1.19 & NA \\
\hline 6 & $\begin{array}{l}\text { No of trees harvested } \\
\text { annually stems/ha }\end{array}$ & 15 & 13 & 2 & 4 & 34 \\
\hline 7 & \multicolumn{3}{|c|}{ Time taken (years) for harvest of mature trees } & & 33.3 & \\
\hline
\end{tabular}

Note: NA - Not Applicable

Table 3: Inventory Data and AAC for an Even-aged Forest (Gadibarah CF Tulsipur Dang) According to CF Inventory Guidelines

\begin{tabular}{|c|c|c|c|c|c|c|}
\hline \multirow[t]{2}{*}{ SN } & \multirow[t]{2}{*}{ Description } & \multicolumn{4}{|c|}{ Diameter class $(\mathrm{cm})$ and no. per ha } & \multirow[t]{2}{*}{ Total } \\
\hline & & $10-14.9$ & $15-19.9$ & 20-29.9 & 30- 40 & \\
\hline 1 & No. per ha & 1,800 & 800 & 300 & 100 & 3,000 \\
\hline 2 & Volume per ha $\left(\mathrm{m}^{3}\right)$ & 77.27 & 76.96 & 58.88 & 48.08 & 231.16 \\
\hline 3 & Annual increment $\left(\mathrm{m}^{3} / \mathrm{ha}\right)$ & 2.32 & 2.31 & 1.77 & 1.46 & 7.86 \\
\hline 4 & AAC ( $\mathrm{m}^{3} /$ ha/year) & 1.74 & 1.73 & 1.32 & 1.08 & 5.87 \\
\hline 5 & $\begin{array}{l}\text { No of trees harvestable } \\
\text { annually/ha }\end{array}$ & 40 & 18 & 7 & 2 & 67 \\
\hline
\end{tabular}

As shown in Table 2 the inventory guidelines suggest that only 4 trees/ha should be removed annually out of 135 trees (30-55 cm dbh) per ha. However this would not be enough to reduce canopy density in the block. In other diameter classes congestion will not be reduced sufficiently within the provisions of these guidelines and this will affect tree growth. Similarly, Table 3 shows that only 2 out of 100 trees per ha could be harvested annually under this system - clearly not enough to affect the increment of the remaining trees or to reduce canopy density.
These examples raise questions such as: Can the AAC prescriptions reduce accumulated stock or canopy density? and Do such prescriptions address protection-oriented forest management by CFUGs? The answer to both these seems to be very unlikely. Prescriptions should be based on the existing density of crops in a forest block. As a result, LFP Mid-west in collaboration with the DFOs and Regional Directorate (RD) have revised and has been practicing a new trees/poles classification system. The prescriptions differ for the first two pole classes i.e. $10-14.9 \mathrm{~cm}$ dbh and $15-19.9 \mathrm{~cm}$ 
$\mathrm{dbh}$ (small and big ballaballi) and larger poles (20-29.9 cm dbh). The lower diameter class is considered as being a pole by communities and for these categories, thinning operations are applicable rather than harvest based on the AAC/MAI system for trees and larger pole categories. If there is congestion in diameter classes $10-20 \mathrm{~cm}$ which needs to be removed through thinning, the inventory guidelines do not make this provision. Use of the inventory guidelines also has constraints for mature forest condition as shown in Table 4.

Table 4: Inventory Data and AAC for Matured Forest, Sarvodaya CF Gadhawa, Dang According to CF Inventory Guideline

\begin{tabular}{|l|l|l|l|l|l|l|}
\hline SN & \multicolumn{1}{|c|}{ Description } & \multicolumn{4}{c|}{ Diameter class $(\mathbf{c m})$ and number per ha } & \multicolumn{1}{|c|}{ Total } \\
\hline $\mathbf{1}$ & No per ha & $\mathbf{1 0 - 1 4 . 9}$ & $\mathbf{1 5 - 1 9 . 9}$ & $\mathbf{2 0 - 2 9 . 9}$ & $\mathbf{3 0 - 7 6}$ & \\
\hline 2 & Volume per ha $\left(\mathrm{m}^{3}\right)$ & NA & 20 & 30 & 60 & 710 \\
\hline 3 & Annual increment $\left(\mathrm{m}^{3}\right)$ & NA & NA & NA & NA & 4.95 \\
\hline 4 & AAC $\left(\mathrm{m}^{3} /\right.$ ha/year $)$ & NA & NA & NA & NA & 2.97 \\
\hline 5 & Average vol./tree $\left(\mathrm{m}^{3}\right)$ & NA & NA & NA & NA & 2.48 \\
\hline 6 & No of tree harvest annually/ ha & NA & NA & NA & NA & 1.20 \\
\hline 7 & Time taken (year) for harvest of mature tree & & 50 & & \\
\hline
\end{tabular}

Note: NA - Not Applicable

Table 4 shows there is a domination of tree classes and only few smaller diameter classes due to dense canopy. In this case, based on the calculated AAC using the Inventory Guidelines, SFM will not be possible because there will be always be a dis-proportionate mixture of diameter classes. Since the AAC basically applies to timber production to ensure a sustainable supply from forests which have been systematically managed from the very beginning, AAC based on the existing guidelines cannot be applied to forest which has only overmature trees of accumulated stock with a dense canopy. Mature forests where the annual increment is decreasing because they are close to the physical rotation cannot be managed based on AAC. In this case, over-mature trees cannot be calculated as growing stock and they need to be removed first to allow regeneration to occur.

In addition to the constraints imposed by the Inventory Guidelines, in many CFs to a greater extent only dead, dying and diseased trees are removed. Although provisions are made in the OPs to extract an AAC, in practice CFUGs harvest even less than that because of their low awareness of the scientific management of CFs and also because they may simply not be allowed to harvest by the DFO.

\section{Outcomes of These Interventions}

In the five Rapti districts, there were a remarkable number of out of date OPs and these were mostly conservative i.e. protectionoriented. To improve their quality, area level workshops were organised where such study reports were presented by LFP and the DFOs. The findings of these studies on prescribed silvicultural treatments in OPs was shared with the regional committee of RD, DFOs and LFP staff. After long discussions it was agreed that silvicultural prescriptions to improve forest condition were needed (Box 1). 


\section{Box 1: Strategic decisions made in favor of active forest management}

A meeting was held in February 2006 (2062-11-10 B.S.) in the presence of DFOs, AFOs, RTO, and LFP staff from five districts of Rapti zone under the chairmanship of Regional Director (RD) of the mid-west development region. The meeting recognised that most of the natural forests in the region are unmanaged, and that there was an accumulated yield in the forests. In addition, as they agreed, there was often congestion in every age group or diameter class. To address these issues, Active Forest Management was suggested as an immediate need and they made the following decisions:

1. In the case of mature and over mature forests, the current estimation of AAC according to growing stock allows for the removal of fewer trees by which the condition of the forest cannot be improved. To encourage regeneration in such forests, harvesting should be significantly more than the current level of the AAC.

2. In the case of pole-stage forest $(10-29.9 \mathrm{~cm} \mathrm{dbh})$ it is better to remove poles by a thinning operation rather than as part of the AAC of the growing stock.

3. In the case of forests where silvicultural operations have not been done earlier, congestion among various diameter classes cannot be removed by harvesting the AAC as per the current growing stock. In such cases, thinning operations should be applied first by defining the stage of the stand which needs to be thinned. Afterwards, the remaining growing stock can be removed according to AAC.

4. According to the growing stock, the forest is classified as overstocked forest (high canopy density), medium stocked forest and under stocked forest (less canopy density). One cannot apply a blanket approach for all these situations. The AAC may be more in overstocked forests and there may be no AAC in under-stocked forest.

5. During a forest inventory AAC as per growing stock is prescribed and performed. But in an over stocked forest, congestion cannot be removed by AAC alone. In such forests, final harvesting is given more importance. Similarly, in under stocked forest, harvesting cannot be performed at all. In such forests AAC is not given importance and silvicultural operations are promoted.

Source: Yadav and Acharaya 2005

After decisions had been made in favour of practical prescriptions at Regional Directorate level, a technical committee was formed for all districts in Rapti zone. The committee supports and coaches DFO and NGO staff and assist them The meeting was a breakthrough event for promoting active forest management and the respective authorities in the five Rapti districts have pursued the implementation of the decisions made. The participants realised that CFs can only fulfil users demand in a sustainable way if forests are managed in more organised and active ways. Today, sustainable management of CFs has become a key issue and is a challenging task for those working in the field of CF (Suwal 2004).

The practice of developing practical silvicultural prescriptions in the LFP working area is against the claims of Suwal (2004), who maintained to prepare practical and simple prescriptions e.g. based on the number and quality of trees that should be removed every year rather than general and complex prescriptions made with a blanket approach.

that sustainable management of CFs is a challenging task for those working in the field of CF. Our experience shows that though the task is challenging because CF objectives are multiple and complex, sustainability can be achieved via the active forest management approach. The result of action research shows that the harvesting in favour of promoting natural regeneration is cheap and successful (Box 2) but it is not yet widely accepted due to the lack of extension.

The arguments behind the active forest management approach are always to promote and emphasize the participation of users in the 


\section{Box 2: Silvicultural operation needed for regeneration}

Whether cultivating agriculture or forestry crops, the basic principles are the same. However, the practice of technology is not applied in forestry whereas it is the same farmers that are involved.

One example could be thinning of crops. This operation is required in both agriculture and forestry. Farmers know well the effect of thinning on an agriculture crop such as maize. They sow densely and thin twice before flowering keeping only the best for a high yield.

Nevertheless, this knowledge is not put in practice in the case of forestry. Some farmers become conservative in the thinning operation, because they have never practiced this in forestry. The results may be a 'jungle' and not a 'forest'. In this case there is a need for intervention to apply appropriate silvicultural operations for the regeneration of desirable species.

Source: Yadav 2004

preparation of more production-oriented OPs. This gives ownership to the users and makes them more acquainted with the process of OP preparation. To fulfil the users forest product needs and to generate income for the CFUGs a simple model of an OP has been developed. In addition to this, increased attention needs to be given to technical training in CF management, especially for Rangers, Forest Guards, LRPs and CFUG members. To accelerate technical work, computer based applications as GPS, GIS and yield calculation tools are used. Several poster and management leaflets have been developed to enhance silvicultural practices towards active forest management.

\section{Revising Community Forestry Operational Plans}

The general quality of OPs is low in terms of assessing the resource condition of particular blocks and defining management objectives. Forest management objectives often do not reflect the actual needs of users and supplies from the forest as a result of management prescriptions are normally traditional, superficial and without adequate links to the management objectives of CFs (Suwal 2004). Looking at these shortcomings of existing OPs site-specific plans were introduced. Prescriptions include the considerations of soil erosion control, natural regeneration promotion and improving the growth of the remaining crop.

Though most of the existing OPs are conservative and timber focused, recently changes have been made in the OPs to include the management of multiple products/services. For example, most newly formed and amended OPs now have provisions for forest resource protection and NTFP management to contribute to enhancing the livelihoods of forest users. Most newly prepared OPs include detailed plans of their resource potentials and users needs are reflected in management objectives. Some CFUGs have biodiversity protection provisions in their OPs and almost all OPs where there are water sources have very clearly mentioned the need to protect water sources as an objective of forest management. In these cases, the harvesting of trees within 50m of a water source is generally prohibited.

\section{Improving Silvicultural Practices}

Natural forests have the potential to deliver multiple environmental and socio-economic benefits. Proper management increases the productivity of the forest and, thereby contributes to achieving management objectives.

Silvicultural activities that increase the productivity of forest ecosystems, such as timely thinning, can increase forest carbon stocks to some extent. However compared with afforestation/reforestation, the effect of varying silvicultural systems on total carbon stocks is relatively low (Dixon et al. 1993). The area of forest under silvicultural treatment is increasing every year and is favoured by more appropriate management objectives and better use of 
forestland. For instance, CFUGs are increasingly emphasising NTFPs management including jadibuti (medicinal and aromatic plants and animals), and production of fodder and other products (e.g. hand made paper). The following facts and figures show changes in silvicultural practices as compared to the past:

- The area under silvicultural treatment has been increasing

- The quantity of forest products harvested is increasing

- The prescriptions of OPs clearly outline the utilisation of forest products including their quantity and quality

- There is a focus on forest land use and multiple cropping to address the needs of CFUGs.

The NTFPs management which is also an integral part of OPs includes activities such as identifying and listing the important species and a resource inventory and estimation of the growing stock and a prescription of harvesting procedures etc. About 30 percent of OPs include such innovative provisions. This progress has challenged the claims of Suwal (2004) that almost all OPs are written in a very general way and provide only vague prescriptions about protection of existing NTFPs. Currently most CFUGs are practicing NTFPs management activities in a planned way and according to the potential of their CFs.

The area of forest under silvicultural treatment (active forest management) is increasing. This area has grown from 2,100 ha in FY 2006-07 to 9,500 ha in FY 2007-08 in the LFP Mid-west area. As the practices have changed so forest product supplies have increased and the perceptions of users have also changed. A few years ago, users would say, "we protect the forest like our kids - how can we fell the trees?" Protection was the only motto. Now they are felling trees as prescribed in their OPs and thus, CF management has moved towards active management rather than protection.

In Rapti zone, about 140 newly prepared OPs and about 400 existing OPs have been amended to include the types of prescriptions drawn up in 2007/08. These have moved beyond perceptions of protection orientation and include elements of active forest management. Now more than 60 percent of CFUGs have very clear and specific provisions for protection and the management of existing NTFPs and many CFUGs are now benefiting from NTFP cultivation and protection. The field based training to identify the harvesting techniques of NTFPs has been very useful.

\section{Enhancing Forest Product Utilisation}

Active forest management is an increasing trend resulting in increased harvests. Forest production has increased 5 -fold in the LFP Midwest area over the past 2 years. This increase in products is partially the result of tending operations such as thinning, pruning, weeding and cleaning. Strategic support is provided to field staff (Rangers, Forest Guards and LRPs) and field-based coaching has been very effective for implementing the operations mentioned in OPs.

Another remarkable change has occured at CFUG level. The CFUGs now realise the importance of their OPs and are following it. This has resulted in CFUGs conducting timely silvicultural operations and has not only increased the availability of forest products but has also reduced collection times particularly in those CFUGs which allow users to collect fuelwood every week. Collection of forest products seasonally as described in the OPs has reduced users collection time. This is particularly beneficial to poor and disadvantaged groups since they can allocate their time seasonally rather than going to the forest every week to meet their forest product needs.

As part of the field based coaching to CFUGs, intensive forest management was piloted in Karri CF of Chailahi VDC of Dang in a forest area of 50 ha. Available forest products are distributed to the users and the surplus is sold commercially from the CFUGs. The resulting income is given in Table 5 . 
Table 5: Income from Forest Operations

\begin{tabular}{|l|r|r|}
\hline $\begin{array}{l}\text { Type of forest } \\
\text { product }\end{array}$ & \multicolumn{2}{|c|}{ Within CFUG (NRs) } \\
\hline Timber & Amount & \multicolumn{1}{|c|}{ NRs } \\
\hline Fuel wood & $1,508 \mathrm{cft}$ & 133,629 \\
\hline Plough, pole & 50 chatta & 87,300 \\
\hline Total & $268 \mathrm{no}$. & 28,408 \\
\hline
\end{tabular}

In LFP Mid-west area, 654 CFUGs have managed 10,632 ha forest (not including the resin tapping area). The upper four districts show a remarkable potential for forest management under resin tapping which could generate income and employment. Some researchers have shown that micro-enterprises, based on processed forest products, with successful marketing can help to generate employment and reduce poverty (e.g. Scherr et al. 2004). But when a cost-benefit analysis was carried out for the LFP Mid-west area, forest based micro enterprises were the least beneficial enterprises indicating difficulties in competing in the open market.

Proper implementation of active forest management provides a significant source of employment and income generation. However, forest protection has also provided employment to the local poor, particularly the hiring of Forest Watchers. About 70 percent of CFUGs pay forest watchers - but they are usually paid a minimum salary only. Some CFUGs have used the poor households as paid labor for their silvicultural operations and some have invested in forest product collection and transportation. As per Forest Regulations (1995) 25 percent of CFUGs income must be spent on forest development activities.

\section{Overall Issues and Constraints}

From a SFM perspective a number of issues exist which hinder active forest management. These are:

- National level strategies regarding different forest management regimes are not in place for government-managed forests, high altitude forest management, and community forest management and policy,

\begin{tabular}{|c|c|c|}
\hline \multicolumn{2}{|c|}{ Outside CFUG (NRs) } & \multirow[t]{2}{*}{ Total (NRs) } \\
\hline Amount & NRs & \\
\hline $8,909 \mathrm{cft}$ & $1,149,000$ & $1,282,629$ \\
\hline 60 chatta & 139,500 & 226,800 \\
\hline \multirow[t]{2}{*}{0} & 0 & 28,408 \\
\hline & $1,288,500$ & $1,537,838$ \\
\hline
\end{tabular}

- The CFUGs are motivated to harvest timber to sell out of the CFUGs. There is less interest in annual silvicultural operations for improving forest condition.

- A lack of understanding about SFM amongst forest managers and practitioners.

- A gap between policy and practice resulting in less interaction on technical matters.

- Large patches of forest supply sufficient products so that CFUGs do not feel the need of active management. As a consequence forest composition is changing towards low quality trees.

- The potential of forestry is less realised by general users.

- Protection oriented management practices, a lack of awareness and institutional capacity of CFUGs to carry out active management of their CF which hinders them obtaining the optimum of forest products

- A lack of specific knowledge and skills among DFOs and NGO staff on the value of NTFP/MAPs management.

- The requirement for various environmental assessments imposed on CFUGs if their forest area is more than 200 ha.

- Fluctuation of NTFPs prices, complex marketing and a reluctance by buyers to pay production costs.

- The OPs used as legal documents for the handover of the forest rather than as a 
working document. As a result, provisions made in the OPs are difficult to translate into practice.

- Double membership of users in CFUGs discourages them to participate in production.

- Provisions in the Inventory Guidelines regarding $A A C$ that are not appropriate for different forest conditions such as evenaged unmanaged forest and over-mature forest. Contradictions are also seen between the Forest Act and Inventory Guidelines in defining tree quality, timber and fuelwood.

- Inadequate capacity of government staff in the provision of technical services to CFUGs.

- Inadequate capacity of users to practice active forest management. A blanket approach to AAC estimation discourages active forest management.

- Lack of a technical audits i.e. post-harvest monitoring and evaluation. The incorporation monitoring outcomes in OPs is inadequate.

\section{CONCLUSION AND RECOMMENDATIONS}

This paper shows that a shift from passive to active management of $\mathrm{CF}$ is possible through developing a SFM strategy. This strategy can act as a guide and provide a joint learning opportunity of the field practice for community groups as well as government and nongovernmental service providers.

The active forest management approach has been instrumental in changing the protection oriented perceptions and perspectives of managing CFs which were largely being underutilised. This paper has provided examples and evidence that CFUGs, with support from LFP, DFO and civil society groups can undertake improved silvicultural practices and equitable sharing of forest products. As a result of implementation of the active forest management strategy, some CFUGs have begun to prepare site-specific forestry plans with clearly defined management objectives and implementation activities for each block within community forests. This has enabled them to reach smaller units of forest and implement effective management beyond the conventional management practice of treating the entire forest as a homogeneous unit. As a result, CFUGs have been able to develop practical and applicable prescriptions for the management of forests based on learning from the field beyond the provisions mentioned in the DoF directives and guidelines.

In addition active forest management has also enabled CFUGs to consider other aspects of forest management such as land use plans, including NTFPs management, biodiversity conservation and water source conservation.

In order to promote this strategy to CFUGs nation-wide, and to ensure effective application, policy reforms are needed including changes to existing rules and guidelines. The involvement of NGOs (or non government service providers) has been highly effective to support CFUGs not only to promote active forest management, but also to provide social mobilisation support to encourage users to get ready for active forest management. A few specific lessons from these experiences are outlined below:

- The CFUGs are enthusiastic to practice active forest management once they are convinced that they need to move beyond their traditional perceptions and practices.

- Existing policies and guidelines can be taken as opportunities for learning. At the same time there is an opportunity to develop practical modifications of existing sets of policies and guidelines. This can be achieved by working together with GoN bodies. 
- For commercial and sustainable supply of forest products from CFUGs an active forest management approach is needed.

- Existing human resources in the DoF are not sufficient to facilitate active forest management and LRPs are critical to fill this gap.

Recommendations for further improvement are given below:

- The CFUGs should be provided with enough support and room to promote active forest management effectively.

- Lessons and suggestions from field level experiences should be widely shared and used to revise existing policies and guidelines.

- Results of various demonstration plots and action research plots need to be widely shared and disseminated.

- Documentation of best practices and dissemination of these at different levels is important to up-scale such innovations

- Development of simple innovations and technologies are needed to ensure their wider adoption by CFUGs and other stakeholders.

- Opportunities for regular updates of knowledge and skills from field staff and service providing agencies are needed to improve the quality of OPs and their effective implementation.

- Support for enhancing commercial production from CFs is needed to increase income and employment and to stimulate active forest management

\section{REFERENCES}

Acharya, K.P. 2002. Twenty-four Years of Community Forestry in Nepal. International Forestry Review, 4: 149-156.
Branney, P. \& Yadav, K.P. 1998. Changes in Community Forest Condition and Management 1994-1998: Analysis of Information from the Forest Resources Assessment Study and Socioeconomic Study in the Koshi Hills. Kathmandu, Nepal: Nepal UK Community Forestry Project. Project report G/NUKCFP/32.

Dixon, R.K., Andrasko, K.J., Sussman, F.G., Lavinson, M.A., Trexler, M.C. \& Vinson, T.S. 1993. Forest Sector Carbon Offset Projects: Near Term Opportunities to Mitigate Greenhouse Gas Emission. Water, Air, and Soil Pollution, 70(1-4): 561-577.

Kanel, K.R. \& Kandel, B.R. 2003. Community Forestry in Nepal: Second Generation Issues. CF Bulletin, 10. Kathmandu, Nepal: Community Forestry Division.

Kanel, K.R. 2004. Economic Impacts of forest Policy Changes: Perspective from Nepal, a Paper Presented in a Workshop at Indian University, Bloomington, USA.

Nurse, M., Tembe, H., Paudel, D. \& Dahal, U. 2004. From Passive Management to Health and Wealth Creation from Nepal's Community Forests. Proceedings of the Fourth National Work-shop on Community Forestry, 4-6 August, 2004. Kathmandu. [pp 127-135]

Scherr, S.J., White, A. \& Kaimowitz, D. 2004. A New Agenda for Forest Conservation and Poverty Reduction: Making Markets Work for Low-income Producers. Forest Trends, Washington, USA.

Shrestha, K. \& Amatya, D. 2000. Protection versus Active Management of Community Forests: In Community Forestry in Nepal. Proceeding of the Workshop on Community Based Forest Resource Management, Nov 2022, 2000, pp 3-17, Joint Technical Review Committee, Kathmandu, Nepal.

Suwal, M.R. 2004. Silvicultural Demonstration Plots-means to Promote Community Based Silviculture Management in Community Forests, a Paper Submitted for the Fourth National Community Forestry Workshop, 4-6 August 2004, Kathmandu, Nepal. 
Yadav, N.P. \& Acharya, M.P. 2005. Workshop Report \& Suggestion on Inventory Guidelines, MW, Dang: LFP (unpublished report).

Yadav, N.P. 2004. Forest User Groups in Nepal: Impacts on Community Forest Management and Community Development, Doctor of Philosophy.
UK: The University of Leeds, School of Geography.

Yadav, N.P., Dev, O.P., Springate Baginski, O. \& Soussan, J. 2003. Forest Management and Utilisation under Community Forestry. Journal of Forest and Livelihood, 3(1): 37-50.

1 Chatta: Is the volume of fuelwood i.e. a stack of $20 \mathrm{ft} \times 5 \mathrm{ft} \times 5 \mathrm{ft}$ of wood pieces less than $2 \mathrm{ft}$ long and $1.5 \mathrm{ft}$ girth 